form. It is seen from Fig. 1 that at $p \mathbf{H ~} 5 \cdot 25$, strontium, present in the cationic form, is quantitatively retained on the resin, while calcium is complexed by the ethylenediamine tetraacetic acid and passes through.

These results were confirmed by using the method to separate strontium from prepared strontium calcium mixtures to which had been added calcium-45 as tracer. The recovery of strontium was checked by eluting the resin with $3 N$ hydrochloric acid and precipitating the strontium as carbonate and weighing. The activity of the carbonate precipitate gave a measure of the degree of contamination of the strontium with calcium. This was shown to be less than 1 per cent.

This ion-exchange recovery of strontium from strontium-calcium mixtures is achieved with the use of very small columns, and should be capable of application to the simple determination of strontium-90 on a routine basis, considerably reducing the time required for each determination.

I wish to acknowledge the assistance of Miss M. Barnett with the experimental work.

Australian Atomic Energy Commission,

$$
\text { P. S. Davis }
$$

Research Establishment, Lucas Heights,

New South Wales. Jan. 21.

${ }^{2}$ Bryant, F. J., Chamberlain, A. C., Morgan, A., and Spicer, G. S., A.E.R.E. $H$ HPIR2056 (1957).

2 Merritt, W. F., Can. J. Chem., 36,425 (1958).

3 Lerner, M., and Rieman, W., Anal. Chem., 26, 610 (1954).

4 Milton, G., and Grummitt, W. E., Can. J. Chem., 35, 541 (1957).

Farabee, L. B., U.S.A.E.C. Report ORNL-1932 (1955).

"Bjerrum, J., Schwarzenbach, G., and Sillen, I. G., "Stability Constants of Metal-ion Complexes" (The Chemical Society, London, 1957).

\section{Detection of Keto-Acids}

Moss of the reported chromatographic work on the identification of keto-acids has involved the paper chromatography of a derivative, usually the 2,4-dinitrophenylhydrazone. A simple technique has been developed in this Laboratory whereby acidic materials which may contain keto-acids are chromatographed directly on Whatman No. 1 paper using a solvent containing ethyl acetate/acetic acid/water $(60: 25: 15 \mathrm{v} / \mathrm{v})$. After irrigation and drying, the papers are sprayed with a saturated alcoholic solution of 2,4-dinitrophenylhydrazine, dried with hot air for 5 min., and then sprayed with an approximately 5 per cent solution of potassium hydroxide in 90 per cent ethanol. The 2,4-dinitrophenylhydrazones which have been formed in situ react to give a variety of colours against an almost colourless background. In general, the derivatives of $\alpha$-dicarbonyl compounds give colours ranging from light blue to dark purple. Derivatives of other carbonyl compounds produce yellow, red or brown spots. The colour given by any one of these derivatives is often distinctive for that compound, and may sometimes serve to differentiate between keto-acids with similar $R_{F}$ values.

This method has proved useful recently in work on the ozonization of aqueous solutions of simple aliphatic acids, when mesoxalic acid may be produced. The oxidation products are chromatographed using 8 method developed here in which a $p \mathrm{H}$ indicator is incorporated in the solvent ${ }^{1}$. Mesoxalic acid or other keto-acids may have $R_{F}$ values similar to those of other non-ketonic acids, and accordingly a second chromatogram without $p \mathrm{H}$ indicator is run and treated in the way described.
As little as $5 \mu \mathrm{gm}$. mesoxalic acid can readily be detected by this method.

\author{
Coal Constitution Laboratory, \\ Department of Mining, \\ University of Birmingham. \\ Jan. 30. \\ ${ }^{1}$ Lawson, G. J., and Hartley, R. D., Biochem. J., 69, 3 P (1958).
}

\section{Equilibration of isoCyanates and isoThiocyanates}

isoThIocyanates have been prepared by several methods ${ }^{1-4}$; I have recently found that they can also be prepared conveniently by the equilibration of isocyanate and isothiocyanate groups. This equilibration occurs slowly at elevated temperatures and appears to be generally applicable to the preparation of isothiocyanates and mixed isocyanates-isothiocyanates.

The reaction is illustrated by the following equation for the preparation of naphthyl isothiocyanate :

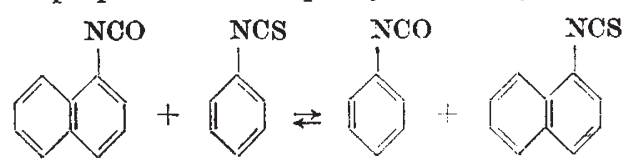

This equilibration reaction may proceed through dimer formation. The yields obtained are fair, and considerable residue is formed. Decomposition leading to tar formation may be caused by the prolonged time at considerably elevated temperature required to establish equilibrium. Further study of the reaction and its variables, particularly acceleration of equilibrium formation by catalytic action, might greatly improve the yields.

25 gm. $\alpha$-naphthyl isocyanate (Matheson, Coleman and Bell) and $21 \mathrm{gm}$. phenyl isothiocyanate (Matheson, Coleman and Bell) were mixed and heated, with stirring, under reflux at a pot temperature of $215-225^{\circ} \mathrm{C}$. for $14 \mathrm{hr}$. During this period the reaction mixture turned yellow and gradually dark brown. Distillation of the reaction mixture yielded four fractions : $12 \cdot 3 \mathrm{gm}$. distillate boiling at $164-168^{\circ} \mathrm{C}$. at atmospheric pressure ; $4.5 \mathrm{gm}$. distillate boiling at $44-46^{\circ} \mathrm{C}$. at $2-3 \mathrm{~mm}$. mercury; $3.4 \mathrm{gm}$. distillate boiling at $85-90^{\circ} \mathrm{C}$. at $1-2 \mathrm{~mm}$. mercury; $13 \cdot 6 \mathrm{gm}$. material boiling at $109-111^{\circ} \mathrm{C}$. at $1 \mathrm{~mm}$. mercury. This last fraction solidified on cooling to room temperature. A dark brown tarry residue $(8.2 \mathrm{gm}$.) was left in the reaction flask. The solid material (m.p. 46-54 $4^{\circ}$ C.) was dissolved in toluene, the small amount of insoluble material filtered off and the toluene stripped off. The resulting white solid, $\alpha$-naphthyl isothiocyanate, weighed $12.8 \mathrm{gm}$. and melted at $56 \cdot 7-57 \cdot 5^{\circ} \mathrm{C}$.

$p$-Bromophenyl isothiocyanate (m.p. $61 \cdot 6-62 \cdot 0^{\circ} \mathrm{C}$.) was prepared by an identical procedure in 35 per cent. yield.

Chemical Engineering Department,

$$
\text { L. C. CASE }
$$

Purdue University,

Lafayette, Indiana. Jan. 10.

'Schrooder, D. C., Chem. Rev., 55, 194 (1955).

2 v. d. Kerk, G. T. M., Pluygers, C. W., and deVries, G., Rec. trav. chim., 74, 1262 (1955).

s Schmidt, E. Kammerl, E., Ross, D., and Zaller, F., Chem. Ann., 594, 233 '(1955).

4 Baxter, J. N., Cymerman-Craig, J.. Moyle, M., and White, R. A., J. Chem. Soc., 659 (1956). 